Surgery for

Congenital

Heart Disease

\title{
Hemidiaphragmatic paralysis increases postoperative morbidity after a modified Fontan operation
}

Zahid Amin, MDa

Doff B. McElhinney, MD

Jennifer K. Strawn, RN, BSN ${ }^{a}$

John D. Kugler, MDa

Kim F. Duncan, MDa

V. Mohan Reddy, MD

Edwin Petrossian, MD ${ }^{\mathrm{b}}$

Frank L. Hanley, MD

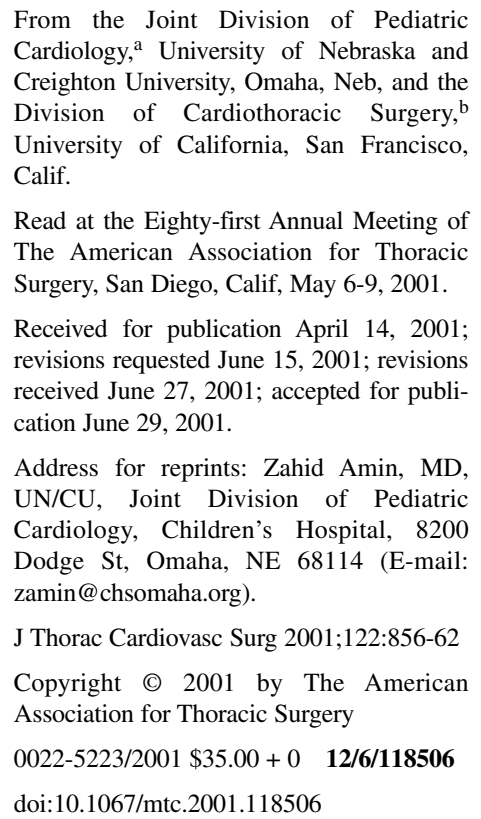

Read at the Eighty-first Annual Meeting of The American Association for Thoracic Surgery, San Diego, Calif, May 6-9, 2001.

Received for publication April 14, 2001; revisions requested June 15, 2001; revisions received June 27, 2001; accepted for publication June 29, 2001.

Address for reprints: Zahid Amin, MD, UN/CU, Joint Division of Pediatric Cardiology, Children's Hospital, 8200 Dodge St, Omaha, NE 68114 (E-mail: zamin@chsomaha.org).

J Thorac Cardiovasc Surg 2001;122:856-62

Copyright (C) 2001 by The American Association for Thoracic Surgery

$0022-5223 / 2001 \$ 35.00+0 \quad \mathbf{1 2} / \mathbf{6} / \mathbf{1 1 8 5 0 6}$

doi:10.1067/mtc.2001.118506

Objectives: After a Fontan procedure, forward pulmonary blood flow is augmented during inspiration because of negative intrathoracic pressure. Total pulmonary blood flow is higher during inspiration. With hemidiaphragmatic paralysis, inspiratory augmentation of pulmonary flow is lost or diminished. The objective of this study was to compare early postoperative morbidity after the modified Fontan operation in patients with and without hemidiaphragmatic paralysis.

Methods: A case-control analysis was performed comparing 10 patients with documented hemidiaphragmatic paralysis against 30 patients without paralysis who were matched for diagnosis, fenestration, and age. The following early postoperative outcomes were assessed: duration of ventilator support, duration of hospital stay, incidence of ascites, prolonged effusions, and readmission.

Results: Preoperatively, there were no significant differences between the 2 groups. However, among the postoperative outcomes, the duration of hospital stay $(25.4 \pm$ 16.6 days vs $10.8 \pm 6.3$ days; $P=.03)$, incidence of ascites $(70 \%$ vs $3 \% ; P<.001)$, prolonged pleural effusions (60\% vs $13 \% ; P=.007)$, and readmission $(50 \%$ vs $7 \%$; $P=.007)$ were significantly greater in patients with hemidiaphragmatic paralysis than in those without hemidiaphragmatic paralysis.

Conclusions: Hemidiaphragmatic paralysis after the modified Fontan operation is associated with an increase in early morbidity. Care should be taken to avoid injury to the phrenic nerve. Patients with prolonged effusions should be evaluated for hemidiaphragmatic paralysis.

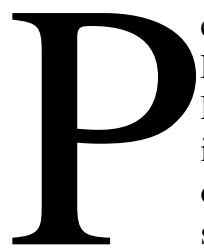

erioperative and long-term survival of patients undergoing a modified Fontan operation has improved significantly over the past decade. ${ }^{1-3}$ Despite the various procedural modifications and the concomitant improvement in survival, patients remain at substantial risk for postoperative morbidity, including ascites and prolonged pleural effusions. ${ }^{4}$ These complications may be related to the physiologic features of a modified Fontan circulation, in which there is no right-sided ventricular pump and the systemic and pulmonary circulations are aligned in series. The systemic 
venous-pulmonary arterial circulation is passive and depends to a great extent on gravity and respiratory variation of intrathoracic pressure. The role of respiratory dynamics in assisting pulmonary blood flow after cavopulmonary anastomosis has been reported. ${ }^{5}$ Systemic venous flow in patients with a Fontan circulation occurs primarily during inspiration, and negative intrathoracic pressure during inspiration increases pulmonary blood flow significantly. 5,6

Complications with systemic venous-pulmonary arterial circulation after a modified Fontan operation have been associated with higher pulmonary artery pressure, heterotaxy syndrome, pulmonary artery distortion, age at operation, the morphology of the single ventricle, the morphology of the systemic atrioventricular valve, ventricular dysfunction, longer cardiopulmonary bypass and ischemic times, atrial arrhythmias, and absence of a fenestration. ${ }^{1,3,7-9}$ The deleterious effects of hemidiaphragmatic paralysis, although speculated, have not been investigated in previous studies. ${ }^{10,11}$ The purpose of this study was to compare postoperative morbidity after a modified Fontan operation in patients with and without hemidiaphragmatic paralysis.

\section{Patients and Methods \\ Patients}

A total of 296 patients underwent a Fontan operation at either the Omaha Congenital Surgery and Cardiology Program (1986-2000) or the University of California, San Francisco (1992-2000). Hemidiaphragmatic paralysis developed in 8 of these 296 patients. Two patients who had had a modified Fontan procedure elsewhere were admitted to our institution with hemidiaphragmatic paralysis. Therefore, this study comprised 10 patients with hemidiaphragmatic paralysis. Hospital records of these patients were reviewed, and 30 control patients who did not have diaphragmatic paralysis (15 from each institution) after a modified Fontan operation during the same time period were selected. These patients were matched for diagnosis, fenestration status, and then for age at the time of the Fontan operation. Patient diagnoses are summarized in Table 1. The modified Fontan procedure was an extracardiac conduit Fontan in 26 patients, a lateral tunnel Fontan in 11, and an atriopulmonary connection in 3 .

\section{Data Analysis}

Perioperative data were collected retrospectively and follow-up data were obtained from the referring cardiologist. Preoperative and operative variables compared between groups included age and weight at the time of the Fontan operation, preoperative mean pulmonary artery pressure, preoperative atrioventricular and semilunar valve regurgitation (mild or greater in severity), preoperative ventricular dysfunction, preoperative arrhythmias, and fenestration status. Postoperative outcome variables assessed included the early postoperative Fontan pressure (measured in the operating room at the conclusion of the procedure), duration of tube thoracostomy, duration of mechanical ventilatory support, duration of postoperative stay in the intensive care unit, duration of hospitalization, development of ascites (qualitatively assessed by physical exami-
TABLE 1. Patient diagnoses

\begin{tabular}{lcc}
\hline Diagnosis & $\begin{array}{c}\text { Hemidiaphragmatic } \\
\text { paralysis }(\mathbf{n = 1 0})\end{array}$ & $\begin{array}{c}\text { Controls } \\
(\mathbf{n}=\mathbf{3 0})\end{array}$ \\
\hline Double-inlet left ventricle & 3 & 9 \\
Hypoplastic left heart syndrome & 3 & 8 \\
Tricuspid atresia & 2 & 6 \\
Heterotaxy single ventricle & 1 & 3 \\
Other single ventricle & 1 & 4 \\
\hline
\end{tabular}

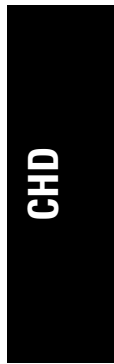

nation and measurement of abdominal girth), prolonged pleural effusions (chest tube drainage $>14$ days), and readmission to the hospital for related issues. Continuous and categorical variables were compared between groups by means of the independent-samples $t$ test and $\chi^{2}$ analysis, respectively. Odds ratios are presented with $95 \%$ confidence intervals. Cox proportional hazards regression was performed to assess for differences in survival over time.

\section{Results}

\section{Preoperative Variables}

Preoperative data are summarized in Table 2 . The only preoperative/operative variable to differ between study patients and controls was the frequency of preoperative atrioventricular valve regurgitation, which was significantly higher in control patients (Table 2).

\section{Early Postoperative Outcomes}

In the 10 study patients, the diaphragmatic paralysis was diagnosed intraoperatively $(\mathrm{n}=1)$ or with echocardiography and/or fluoroscopy $(n=9)$. In all cases, the diaphragmatic paralysis was unilateral, with paralysis of the left hemidiaphragm in 6 patients and the right hemidiaphragm in 4.

There were no early deaths. Patients with hemidiaphragmatic paralysis had a significantly higher early postoperative Fontan pressure, longer duration of tube thoracostomy and hospital stay, higher frequency of ascites and prolonged pleural effusions, and a greater likelihood of readmission for related issues (Table 3).

Hemidiaphragmatic plication was performed in 5 of the 10 study patients. One patient, in whom damage to the phrenic nerve was identified intraoperatively, underwent plication at the time of the modified Fontan operation. The other 4 patients underwent diaphragmatic plication between 4 and 10 weeks postoperatively. In our earlier experience, there were 5 patients with hemidiaphragmatic paralysis in whom plication was not performed. Protein-losing enteropathy ultimately developed in 2 of these patients, and the remainder recovered after prolonged morbidity.

\section{Follow-up}

At a median post-Fontan follow-up of 3.1 years (0.3-15 years), there were 2 deaths, which occurred 3 and 7 years after the modified Fontan procedure. Both deaths were in patients 
TABLE 2. Preoperative/operative variables in patients who did and did not have hemidiaphragmatic paralysis after modified Fontan procedure

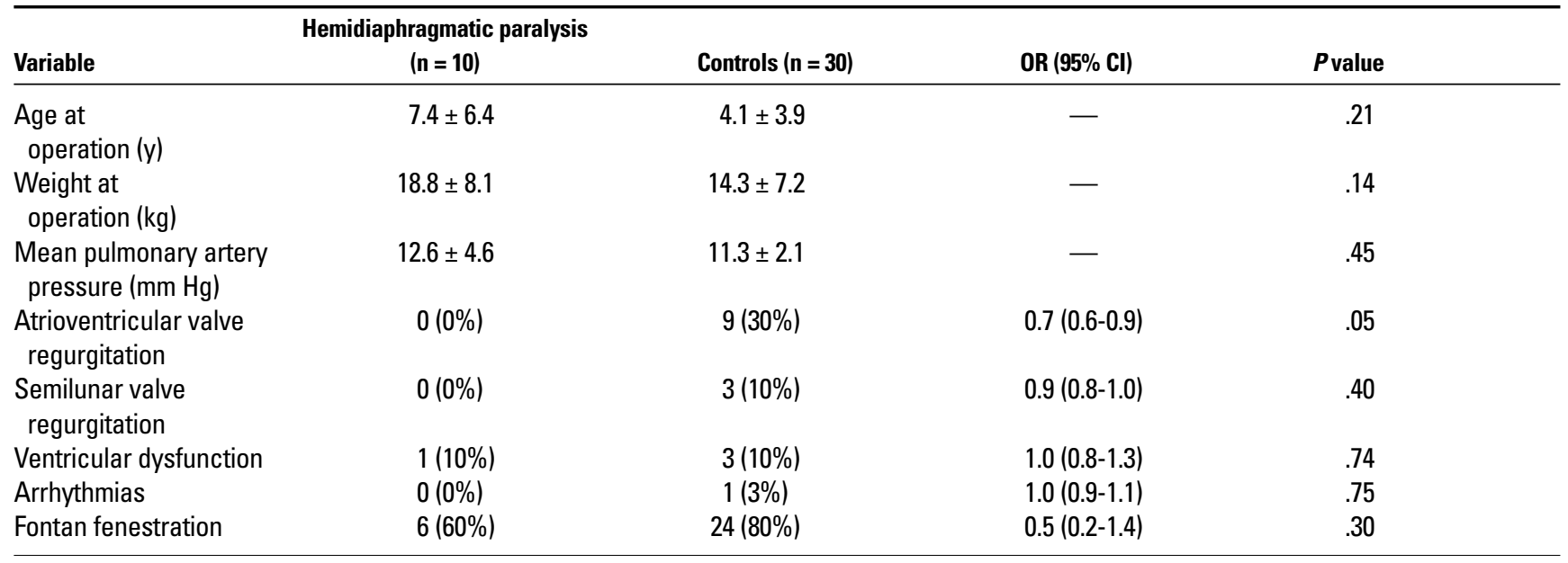

$O R$, Odds ratio; $\mathrm{Cl}$, confidence intervals.

with hemidiaphragmatic paralysis whose postoperative course was complicated by ascites, prolonged effusions, and readmission. As explained above, both of these patients had protein-losing enteropathy. On Cox regression analysis, there was no significant difference in actuarial survival between patients with and without hemidiaphragmatic paralysis.

\section{Discussion}

The classic Fontan operation has undergone several modifications over the past 2 decades. Abandonment of the atriopulmonary connection in favor of the total cavopulmonary connection, either by means of a lateral tunnel or an extracardiac conduit, has been based on an enhanced understanding of the flow dynamics of the Fontan circulation. ${ }^{12}$ Although the various surgical modifications have yielded an improvement in survival, ${ }^{13}$ early postoperative complications such as prolonged pleural effusions and ascites remain a problem in a substantial number of patients and are associated with increased hospital stay and readmission after discharge. Creation of a fenestration or an adjustable atrial septal defect in the Fontan pathway appears to decrease the likelihood of pleural effusions, although at the expense of lower systemic saturations. ${ }^{14}$ One recent study suggests that antegrade hepatic venous flow is increased during inspiration in patients with the fenestrated Fontan operation. This is accomplished by reduction in the systemic venous pressure and the systemic venous resistance. ${ }^{15}$ In addition, reports have suggested that staging toward the Fontan procedure with a bidirectional superior cavopulmonary connection, ${ }^{16}$ administration of aprotinin, ${ }^{17}$ preoperative embolization of systemic-pulmonary arterial collaterals, ${ }^{18}$ and modified ultrafiltration ${ }^{19}$ reduce the incidence and severity of post-Fontan pleural effusions.

Hemidiaphragmatic paralysis is relatively uncommon after pediatric cardiac surgery. ${ }^{20,21}$ In our series, hemidi- aphragmatic paralysis developed in 8 of 296 patients who underwent a modified Fontan operation, giving an incidence of $2.7 \%$. The incidence is similar to previous reports in patients with complex congenital cardiac defects. ${ }^{20,21}$ When present, it seems to increase postoperative morbidity and mortality, but there are no data on the effect of this complication on early postoperative outcomes after a modified Fontan operation. In this case-control study of 10 patients with hemidiaphragmatic paralysis and 30 matched controls, hemidiaphragmatic paralysis was not associated with an increase in mortality, but it did result in a significant increase in morbidity, including pleural effusions, ascites, duration of hospital stay, and need for readmission. Patients with hemidiaphragmatic paralysis also had a significantly higher Fontan pressure, although the magnitude of this difference was small and its relationship with the complications that occurred in these patients is difficult to ascertain. In general, hemidiaphragmatic paralysis in pediatric patients undergoing cardiac surgery is associated with a prolonged stay in the pediatric intensive care unit, increased ventilator dependence, and higher mortality. However, in our study, there was no increase in immediate postoperative mortality, duration of ventilator dependence, or duration of stay in the intensive care unit. Positive-pressure ventilation is detrimental to the Fontan circulation, and extubation leads to loss of positive intrathoracic pressure, which is favorable to patients with a modified Fontan connection, even if they have hemidiaphragmatic paralysis.

After completion of a modified Fontan operation, a series of changes occur that affect systemic venous return. First, because of the lack of a right-sided pump, the pulsatility of flow in the pulmonary arteries decreases substantially. Normally, pulsatile flow helps keep the distal vessels patent, and a loss of pulsatility effectively increases after- 
TABLE 3. Postoperative outcomes in patients who did and did not have hemidiaphragmatic paralysis after modified Fontan procedure

\begin{tabular}{lcccc}
\hline Variable & $\begin{array}{c}\text { Hemidiaphragmatic } \\
\text { paralysis }(\mathbf{n = 1 0})\end{array}$ & Controls $\mathbf{( n = 3 0 )}$ & OR (95\% Cl) & P value \\
\hline Postoperative Fontan pressure (mm Hg) & $13.9 \pm 1.8$ & $11.8 \pm 1.6$ & - & .01 \\
Duration of tube thoracostomy (d) & $23.3 \pm 21.1$ & $7.0 \pm 4.9$ & - & .04 \\
Duration of ventilator support (h) & $36.0 \pm 20.4$ & $26.2 \pm 9.6$ & - & .18 \\
Duration of ICU stay (d) & $4.3 \pm 3.8$ & $2.6 \pm 1.3$ & - & .15 \\
Duration of hospitalization (d) & $25.4 \pm 16.6$ & $10.8 \pm 6.3$ & $67(6.1-752)$ & .03 \\
Ascites & $7(70 \%)$ & $1(3 \%)$ & $10(1.9-50)$ & .001 \\
Prolonged pleural effusions & $6(60 \%)$ & $4(13 \%)$ & .007 \\
Readmission & $5(50 \%)$ & $2(7 \%)$ & .007 \\
\hline
\end{tabular}

$O R$, Odds ratio; $\mathrm{Cl}$, confidence intervals; ICU, intensive care unit.

load because of an elevation of pulmonary arterial impedance. Second, the systemic venous circulation is in series with the pulmonary venous circulation, which may add additional resistance to the systemic venous return..$^{11,12,22}$ Third, patients with a modified Fontan circulation may be at risk for transient ventricular dysfunction for a variety of reasons. It also appears that the importance of gravity in facilitating systemic venous return is accentuated in patients with a Fontan circulation. ${ }^{10}$ Thus, systemic venous return may be impeded by increased resistance, ventricular dysfunction, and heightened gravitational variation. It seems plausible that negative intrathoracic pressure generated by a normally functioning diaphragm becomes a more important factor contributing to optimum systemic venous and pulmonary arterial circulation.

Studies in normal subjects have shown that spontaneous breathing provides additional energy for antegrade systemic venous flow. ${ }^{23}$ In patients with a modified Fontan circulation, the negative intrathoracic pressure generated during respiration assumes a greater importance. In patients with the Fontan circulation, $63 \%$ of systemic venous flow is during inspiration, and there is a $24 \%$ increase in flow during inspiration. ${ }^{5,6,24}$ Accordingly, disturbances in ventilatory mechanics in patients with a Fontan circulation can lead to significant hemodynamic compromise. Our study confirms that hemidiaphragmatic paralysis can lead to significant complications after a modified Fontan operation.

In adults, hemidiaphragmatic paralysis decreases pulmonary function by approximately $25 \%$, but the stability of the adult rib cage and strength of the accessory muscles of respiration help to compensate for the decreased diaphragmatic function. ${ }^{25}$ In contrast, children undergoing a Fontan operation are less likely to benefit from these factors, insofar as the stability and musculature of the thoracic cage may not be as prominent, in part because most of these patients have had multiple operations, including one or more thoracotomy incisions in some cases, which may limit thoracic expansion. In addition, some of these patients are chroni- cally sick and have lower than normal muscular strength. Thus, intact diaphragmatic function may be especially important in maintaining normal respiratory dynamics, including the generation of negative intrathoracic pressure. ${ }^{25}$ In patients with hemidiaphragmatic paralysis, the mediastinum shifts toward the contralateral side, thereby reducing air entry to the contralateral lung. Underlying lung disease or decreased compliance in patients with congenital heart disease may further compound this effect. The paradoxical movement of the diaphragm does not lower the intrathoracic pressure and the cardiopulmonary interaction is reduced.

Interestingly, none of our patients had hemidiaphragmatic paralysis after the bidirectional Glenn or hemi-Fontan operation. Antegrade flow in the superior vena cava after the bidirectional Glenn operation is aided by gravity. Also, we speculate that patients with hemidiaphragmatic paralysis after the Glenn operation fare better than patients who have hemidiaphragmatic paralysis after completion of the Fontan operation.

Although it is difficult to avoid phrenic nerve injury in all patients, our results suggest that the surgeon should make meticulous effort to avoid injuring the phrenic nerve, especially in patients with single ventricle morphology. Patients with persistent pleural effusions after a modified Fontan operation should be evaluated for hemidiaphragmatic paralysis early, with echocardiography or fluoroscopy, if there is concern about this diagnosis. Although only 5 of 10 patients underwent plication of the diaphragm, we believe that once the diagnosis is established, diaphragmatic plication should be carried out earlier rather than later. Plication will help keep the lung expanded and improve antegrade flow of the systemic venous circulation. The last 2 patients who had early diaphragmatic plication had significantly lower morbidity and were discharged to their homes within a week. The patient who had plication intraoperatively did not have prolonged morbidity. Unfortunately, the patient volume is small to reach a definite conclusion about early plication. 
More detailed functional follow-up analysis will be necessary to determine the efficacy of plication.

\section{Study Limitations}

This study has several important limitations. Because the patients underwent surgery at 2 institutions, it is possible that differences in management may have biased our results. There were no significant differences between control patients from each institution or between study patients from each institution, in preoperative or postoperative variables, so this consideration was not a major confounding factor. Also, the approach to diaphragmatic plication changed over time, which makes it difficult to assess the impact of this intervention on outcomes. Coupled with the lack of long-term functional data (eg, exercise, pulmonary function, and systemic venous-pulmonary arterial hemodynamics), we are not able to assess the effect of diaphragmatic plication or make a strong recommendation about the utility of this procedure. Although we lack the data to make such a recommendation, our empirical impression is that patients who undergo diaphragmatic plication fare better. This theory is supported by the fact that 2 of the patients in this series who did not have a plication had protein-losing enteropathy and died as a result.

\section{References}

1. Mosca RS, Kulik TJ, Goldberg KS, Vermilion RP, Charpie JR, Crowley DC, et al. Early results of the Fontan procedure in one hundred consecutive patients with hypoplastic left heart syndrome. $J$ Thorac Cardiovasc Surg. 2000;119:1110-8.

2. Stamm C, Friehs I, Mayer JE, Zurakowski D, Triedman JK, Moran AM, et al. Long-term results of the lateral tunnel Fontan operation. $J$ Thorac Cardiovasc Surg. 2001;121:28-41.

3. Gentles TL, Mayer JE, Gauvreau K, Newburger J, Lock JE, Kupferschmid JP, et al. Fontan operation in five hundred consecutive patients: factors influencing early and late outcome. $J$ Thorac Cardiovasc Surg. 1997;114:376-91.

4. Mayer JE, Bridges ND, Lock JE, Hanley FL, Jonas RA, Castaneda AR. Factors associated with marked reduction in mortality for Fontan operations in patients with single ventricle. J Thorac Cardiovasc Surg. 1992;103:444-52.

5. Redington AN, Penny D, Shinebourne EA. Pulmonary blood flow after cavopulmonary shunt. Br Heart J. 1991;65:213-7.

6. Penny DJ, Redington AN. Doppler echocardiographic evaluation of pulmonary blood flow of the Fontan operation: the role of the lungs. Br Heart J. 1991;66:372-4.

7. Peters NS, Somerville J. Arrhythmias after the Fontan procedure. $\mathrm{Br}$ Heart J. 1992;68:199-204.

8. Bridges ND, Jonas RA, Mayer JE, Falangan MF, Keane JF, Castaneda AR. Bidirectional cavopulmonary anastomosis as interim palliation for high-risk Fontan candidates. Circulation. 1990;82:1681-9.

9. Jonas RA. Indications and timing for the bidirectional Glenn shunt versus the fenestrated Fontan circulation. J Thorac Cardiovasc Surg. 1994;108:522-4.

10. Hsia T, Khambadkone S, Redington AN, Migliavacca F, Deanfield JE, de Leval MR. Effects of respiration and gravity on infradiaphragmatic venous flow in normal and Fontan patients. Circulation. 2000; 102(Suppl):III-148-53.

11. Hsia T, Khambadkone S, Deanfield JE, Taylor JF, Migliavacca F, de Leval MR. Subdiaphragmatic venous hemodynamics in the Fontan circulation. J Thorac Cardiovasc Surg. 2001;121:436-7.
12. de Leval MR, Kilner P, Gewillig M, Bull C. Total cavopulmonary connection: a logical alternative to atriopulmonary connection for complex Fontan operation. J Thorac Cardiovasc Surg. 1988;96:682-95.

13. Knott-Craig CJ, Danielson GK, Schaff HV, Puga FJ, Weaver AL, Driscoll DD. The modified Fontan operation. J Thorac Cardiovasc Surg. 1995;109:1237-43.

14. Airan B, Sharma R, Choudhary SK, Mohanty SR, Bhan A, Chowdhari UK, et al. Univentricular repair: Is routine fenestration justified? Ann Thorac Surg. 2000;69:1900-6.

15. Hsia T-Y, Khambadkone S, Redington AN, de Leval MR. Effect of fenestration on the sub-diaphragmatic venous hemodynamics in the total-cavopulmonary connection. Eur J Cardiothorac Surg. 2001;19: 785-92.

16. DeLeon SY, Idriss FS, Ilbawi MN, Muster AJ, Paul MH, Cole RB, et al. The role of the Glenn shunt in patients undergoing the Fontan operation. J Thorac Cardiovasc Surg. 1983;85:669-77.

17. Tweddell JS, Berger S, Frommelt PC, Pelech AN, Lewis DA, Fedderly RT, et al. Aprotinin improves outcome of single-ventricle palliation. Ann Thorac Surg. 1996;62:1329-36.

18. Spicer RL, Uzark KC, Moore JW, Mainwaring RD, Lamberti JJ Aortopulmonary collateral vessels and prolonged pleural effusions after modified Fontan procedures. Am Heart J. 1996;131:1164-8.

19. Koutlas TC, Gaynor W, Nicolson SC, Steven JM, Wernovsky G, Spray TL. Modified ultrafiltration reduces postoperative morbidity after cavopulmonary connection. Ann Thorac Surg. 1997;64:37-42.

20. Leeuw M, Williams JM, Freedom RM, Williams WG, Shemie SD, McCrindle BW. Impact of diaphragmatic paralysis after cardiac surgery in children. J Thorac Cardiovasc Surg. 1999;118:510-7.

21. Tonz M, Segesser LK, Mihaljevic T, Arbenz A, Stouffer UG, Turina M. Clinical implications of phrenic nerve injury after pediatric cardiac surgery. J Pediatr Surg. 1996;31:1265-7.

22. de Leval MR The Fontan circulation: What have we learned? What to expect? Pediatr Cardiol. 1998;19:316-20.

23. Rabinovinci $\mathrm{N}$, Navot $\mathrm{N}$. The relationship between respiration, pressure and flow distribution in the vena cava and portal and hepatic veins. Surg Gynecol Obstet. 1980;66:372-4.

24. Fogel MA, Weinberg PM, Hoydu A, Hubbard A, Rychik J, Jacobs M, et al. The nature of flow in the systemic venous pathway measured by magnetic resonance blood tagging in patients having the Fontan operation. J Thorac Cardiovasc Surg. 1997;114:1032-41.

25. Fakhoury KF, Seilheimer DK. In: Garson A, Bricker JT, Fisher DJ, Neish SR, editors. The science and practice of pediatric cardiology. Vol II, 2nd ed. Baltimore: Williams \& Wilkins; 1998. p. 2813-32.

\section{Discussion}

Dr Marshall L. Jacobs (Philadelphia, Pa). I rise to commend Dr Amin on an articulate presentation of an important observation that phrenic nerve injury during the Fontan procedure is associated with significant morbidity, primarily manifest as a high incidence of ascites and prolonged pleural effusions.

From the time that Professors Fontan and Kreutzer introduced their procedures, it has been assumed that negative intrathoracic pressure was a principal driving force behind blood movement into the pulmonary circulation in the absence of a pumping chamber. Although this is absolutely true, it is perhaps a bit of an oversimplification.

In 1997, in The Journal of Thoracic and Cardiovascular Surgery (1997;114:1032-41), our cardiology colleague in Philadelphia, Dr Mark Fogel, published an interesting report in which magnetic resonance bolus blood tagging was used to study blood flow in the systemic venous pathway of 22 of our patients having the Fontan operation. Data acquisition was gated to events in the cardiac cycle and to respiration. Not surprisingly, maximal flow was near the end of systole and early diastole and in inspiration. However, when a quantitative analysis was undertaken, $70 \%$ of 
flow was dependent on events in the cardiac cycle and $30 \%$ was dependent on the respiratory cycle. The simple reduction of inspiratory coupling to cardiac output is probably insufficient to explain the very significant morbidity that was observed in your patients.

Looking for an explanation, we turn to some fascinating recent studies that were done by Mr de Leval and his colleagues at Great Ormond Street, which shed some light on this problem. Trying to distill a simple message from very complex studies, their studies of infradiaphragmatic circulatory dynamics in normal persons and in Fontan patients revealed that in the presence of normal cardiovascular circulation, hepatic flow is highly dependent on inspiration; portal flow ordinarily is not. There ordinarily is a transhepatic venous gradient, and portal flow is independent of inspiration. However, they observed in Fontan patients that portal flow is dependent on hepatic flow and thus is highly dependent on inspiration, which leads to the inference that altered respiratory mechanics after the Fontan operation would have a dramatic effect on the splanchnic circulation and on portal venous flow.

Did you observe protein-losing enteropathy as a late complication in any of these patients with hemidiaphragmatic paralysis, and was it an element in the 2 late deaths among the patients in that subgroup?

The second interesting area for further consideration is the mechanism of phrenic nerve injury and, as you alluded, the important strategies to avoid it. Hemidiaphragmatic paralysis is also a potential complication of the staging procedures that lead up to the Fontan operation. However, at the time of the Fontan procedure, this injury could be the result of the insertion of neck lines, could be a cold-related injury, could be related to dissection of the superior and inferior venae cavae for cannulation and for tourniquet occlusion, or could occur at the time of dissection of the aorta for purposes of crossclamping, particularly in patients with an augmented aorta such as after a Norwood or a Damus procedure.

Many of us know something about the Fontan operation as performed in San Francisco, where Dr Hanley tells us that they usually avoid aortic crossclamping, generally avoid hypothermia, and frequently avoid cardiopulmonary bypass entirely.

Taking a very different approach to the Fontan operation, in our practice we use a single venous cannula, deep hypothermia, and a very brief period of circulatory arrest. We believe that the zero incidence of phrenic injury in our series of 72 patients is probably related to avoidance of caval dissection, caval cannulation, and the application of caval tourniquets.

Can you identify any features in the surgical method that put your patients at risk for phrenic nerve injury and how might we alter our surgical approaches to avoid this very serious problem?

Dr Amin. Thank you very much, Dr Jacobs.

The 2 patients who died did have protein-losing enteropathy, but the other 3 patients who did not have diaphragmatic plication and the 5 patients who did have diaphragmatic plication did not have protein-losing enteropathy. All of these patients were catheterized after a certain time, and the pulmonary artery pressures were at the upper limits of what we consider normal for patients having the Fontan operation, around $15 \mathrm{~mm} \mathrm{Hg}$. These pressures were about $2 \mathrm{~mm} \mathrm{Hg}$ higher than those of patients who did not have hemidiaphragmatic plication. I agree with you that altered respiratory mechanics have a dramatic effect on the splanchnic circulation. However, ultimately I think effusions resolved whether we performed plication or not. I must emphasize that the 2 patients who died did have protein-losing enteropathy.

Your second question is very difficult to answer. Because this is a retrospective study, we really cannot identify among those 10 patients what we did and what we could have done to prevent phrenic nerve injury. I guess meticulous dissection, minimal cauterization, and extreme caution will be the way to go.

Dr Peter B. Manning (Cincinnati, Ohio). You recommend that diaphragmatic plication be done early in the management of this problem. Diaphragmatic plication for phrenic nerve paralysis is a treatment for ventilatory insufficiency in newborns who have diaphragmatic paralysis, and it has been widely shown to take care of that problem. However, that is a totally different physiologic problem from what you are dealing with now, which is mediastinal shift, paradoxical ventilation.

Do you have evidence that diaphragmatic plication did have an impact on those patients who were so treated? I am not completely convinced that we are dealing with the same physiology, nor am I completely convinced that diaphragmatic plication will change the physiology that is leading to the increased morbidity in this population.

Dr Amin. I can definitely speak for 2 patients of these 10 patients. Their results prompted me to write this paper. One patient had plication about 4 months ago and the second patient 1 year ago. Both of these patients were readmitted after discharge because of pleural effusions and ascites. Once hemidiaphragmatic paralysis was confirmed and the diaphragm was plicated, their condition improved and they were discharged to their homes within 3 days. I think addressing this issue early is definitely beneficial.

In 1 of our patients, hemidiaphragmatic paralysis was diagnosed intraoperatively, and we plicated the diaphragm during the same operation. This patient did not have prolonged morbidity. I strongly believe that an aggressive approach is the key in patients with hemidiaphragmatic paralysis.

Dr Thomas L. Spray (Philadelphia, Pa). Did you notice any difference based on the diaphragmatic paralysis in relationship to where the heart pointed? The heart occupies space in the chest, and the pulmonary flow distribution may be abnormal, too, depending on that characteristic. For example, did you look at perfusion studies before and after diaphragmatic plication to see if, in fact, the physiology is that all the flow goes to the ventilated and normal diaphragm side of the chest?

Dr Amin. That is a very good question. No, we did not do perfusion studies. I might also add that perfusion studies are difficult to interpret after the Fontan operation because the relative flow to the lungs depends on the site where technetium 99m macroaggregated albumin is injected. Again, this is a retrospective study. Many things could have been done, but that was not in our control.

Dr Florentino Vargas (Buenos Aires, Argentina). I understand that these patients are at greater risk for postoperative complications, and you addressed all of the deaths.

I saw 2 patients after the Fontan operation, in the very long term, who belong to this group. Therefore, just fixing the diaphragm probably does not solve the problem.

My question goes a little before the Fontan operation. What about the patients with bidirectional Glenn shunts in whom the diaphragm 
has been paralyzed? Those mainly at risk are the group of patients in whom augmentation of the pulmonary arteries has to be done because of peripheral distortions of the pulmonary artery. In this particular group of patients, adhesions, hemostasis, and dissection will put the phrenic nerve in more danger. Will they be potential candidates for having a phrenic nerve palsy at the time of their bilateral Glenn shunt? After that, if you have fixed these diaphragms, during the postoperative period after the Glenn shunt, will you consider these patients at higher risk for the future Fontan operation?

Dr Amin. Thank you. After the bidirectional Glenn shunt, pulmonary circulation is not as dependent on respiration, that is, negative intrathoracic pressures, as it is after the Fontan operation. Gravity plays a role in superior vena caval flow to the pulmonary arteries. Therefore, we encounter fewer problems after hemidiaphragmatic plication in patients with the hemi-Fontan operation or bidirectional Glenn shunt.

Once you have connected the inferior vena cava to the pulmonary arteries, you can have significant problems. As Dr Jacobs pointed out, flow from the hepatic veins is dependent on inspiratory pressures, and the hepatic vein exerts some resistance to the splanchnic system, because splanchnic veins drain to the inferior vena cava through the hepatic veins. After the bidirectional Glenn anastomosis, inferior vena caval flow remains part of the systemic circulation.

Now, will I consider them as high-risk patients for the Fontan operation? I think so. I would plicate the diaphragm at the time of doing the Fontan operation.

Dr Joseph J. Amato (Chicago, Ill). Have you ever considered using phrenic nerve pacing in these patients? Our center has a respiratory laboratory in which we do phrenic nerve pacing. We have never considered using it in these types of patients with hemidiaphragmatic paralysis, but I am wondering whether this might be a solution to your problem.

Dr Amin. Thank you for your question, Dr Amato. As you know, this is a retrospective study and therefore limited with regard to interventions. Phrenic nerve pacing sounds like a good idea and certainly something to consider. I believe that in the presence of phrenic nerve injury, the diaphragm should be plicated sooner rather than later to take care of the hemodynamic problems. We will certainly keep pacing in mind in the future.

\section{Bound volumes available to subscribers}

Bound volumes of The Journal of Thoracic and Cardiovascular Surgery are available to subscribers (only) for the 2001 issues from the Publisher, at a cost of $\$ 134.00$ for domestic, $\$ 165.85$ for Canadian, and $\$ 155.00$ for international subscribers for Vol 121 (January-June) and Vol 122 (July-December). Shipping charges are included. Each bound volume contains a subject and author index and all advertising is removed. Copies are shipped within 60 days after publication of the last issue of the volume. The binding is durable buckram with the Journal name, volume number, and year stamped in gold on the spine. Payment must accompany all orders. Contact Mosby, Subscription Customer Service, 6277 Sea Harbor Dr, Orlando, FL 32887, USA; phone 800-654-2452 or 407-345-4000.

Subscriptions must be in force to qualify. Bound volumes are not available in place of a regular Journal subscription. 